Neuroscience in Europe

\section{Zürich}

Biological research in Europe could be much more effective with more coordination between the research efforts of the various European nations. Neuroscience suffers particularly, because of its varied approaches. Some practical remedies were proposed at a special symposium at the European Neuroscience Association annual meeting, held here last week.

Attendance at the meeting is symptomatic of the problem - fewer than 2,000 people participated, out of an estimated 8,000 neuroscientists active in Europe. A disproportionately large number came from the smaller nations, and poorer participation from the larger countries means that the opportunity for making contacts cannot be fully exploited. Competition from specialist societies leads to further fragmentation that also damages interdisciplinary exchange.

Michel Cuénod, retiring president of the association and director of the Brain Research Institute in Zürich, identified the country-based structure of academic careers and research funding as a major problem: individuals tend to give first priority to national collaborations and meetings. But Europe has the advantage of large centres within easy reach of each other, which could be exploited, suggested Philippe Lazar (director-general, INSERM, Paris), by establishing supranational networks to concentrate effort on timely and important problems; these should involve regular short visits between laboratories rather than long-term exchanges. A cheap travel pass for scientists would remove one serious obstacle to frequent interchanges.

Funding such networks is more problematical: asking governments to contribute to European budgets may weaken national research funding. The main support for exchange visits at the moment comes from the European Science Foundation, whose neurosciences programmes are already oversubscribed.

An alternative, modelled on a scheme already operating in Switzerland, was proposed by $H$. van der Loos, professor of anatomy at the University of Lausanne. European-based drug companies should be asked to contribute to a supranational research fund, supervised by a committee of scientists who would determine priorities. The fund should be used for supporting basic research, with no industrial strings attached. Such a scheme might also help to solve a major problem facing the pharmaceutical industry: how to support basic science, the main source of industrially useful innovations, without bleeding the universities of their best talents. \title{
Superconductivity in UK suffers from apathy in industry
}

\section{Cambridge}

SUPERCONDUCTIVITY research in Britain is being held back because industry is unwilling to invest. Of $£ 16$ million available in public funds, only about $£ 10$ million has been spent. This is partly because superconductivity is officially classed as an advanced technology project and one of the funding criteria is that there must be three partners from industry or two from industry and one higher education institute. Sir Martin Wood, who chairs the national committee, said at a symposium on high-temperature superconductors at the University of Cambridge last week, that industry has been "somewhat slow" in coming forward. The attitude of industry, he said, is that if something is being done in Japan and the United States, then Britain will not be able to keep up and that if those countries are not involved then it is not worth doing.

Funds in Britain for high-temperature superconductivity are not available on the scale of funding elsewhere, said Wood, and if industry is to benefit then it must target specfic areas where applications are seen to be likely. This contrasts with the situation in Japan where the fact that commercial benefit may be distant does not discourage investment in basic research on a large scale. And the situation is similar in the United States, where the attitude towards applications is illustrated by one researcher's comment at a conference in San Francisco last month: Dr Jan Evetts, a director of the new interdisciplinary research centre at Cambridge, reported the delegate as replying, when asked of the possible applications of a superconducting thin film, that you might be able to "scratch a message on it and send it through the post".

But in Britain, the funding arrangements require that industry is involved and industry wants to see applications on the horizon. Dr Derek Howarth of the Research and Technology Policy unit of the Department of Trade and Industry (DTI), speaking at the symposium, said that the present funding arrangements will probably change next year, possibly in an attempt to alert industry to market opportunities. Funds for high-temperature superconductivity will then be channelled through the government's LINK scheme. Whether the move will have the desired effect is debatable, but it may unlock some of the funds available, because a project will be required to have only one industrial partner. There will also have to be one partner from the science base involved. The switch will mean that most of the projects might change quite dramatically, said Howarth.
Funds for research in high-temperature superconductivity also come through the Science and Engineering Research Council (SERC), which spends $£ 2$ million a year, and through a joint arrangement between the council and the Ministry of Defence. Between $£ 3$ million and $£ 5$ million is available through this joint scheme but remains unspent. Peter Anderson of the ministry said this is because the scheme is not well known and because some researchers are hesitant about getting involved in defence-related research.

After finding funds, researchers in Britain are faced with another problem: how to keep up with developments in the rest of the world. Because of the expense, there is no comprehensive database in this country. Both the SERC and the DTI have examined bids for a database and rejected them on the grounds of cost. Now work is underway to establish links with existing databases in Europe.

Another obstacle to advances in this field is a shortage of postgraduate researchers. Short-term posts are not always attracting the required workers.

Researchers at the symposium also expressed concern that unless more money is spent on technology based on conventional superconductors, then when high-temperature superconductors are at an exploitable stage Britain will not have the technology to build on in order to reap the commercial benefits.

The new interdisciplinary research centre which hosted the symposium was set up this year with $£ 5.3$ million from the government. Thirty researchers are employed at the centre and there are posts available for another 30 . As yet there are no contributions from industry, but the director, Dr Peter Duncumb, hopes eventually to have 20 per cent industrial sponsorship.

Christine McGourty

\section{Drug testing at Seoul}

\section{London}

A \$3-MILLION drug-testing laboratory is being set up for the Olympic Games in Seoul. The laboratory will operate 24 hours a day for two weeks and will test 2,000 urine samples for 4,000 banned substances. With the equipment, which has been supplied by Hewlett-Packard, chemists will test for five different classes of drugs: stimulants, such as amphetamines; narcotics, such as morphine; anabolic steroids, which accelerate muscle development; beta blockers, which reduce heart rate; and diuretics, which dilute urine to reduce the presence of other banned substances.

Christine McGourty 